\title{
Unconfined Mechanical Properties of Nanoclay Cement Compound Modified Calcareous Sand of the South China Sea
}

\author{
Wei Wang, ${ }^{1}$ Jian $\mathrm{Li}^{1}{ }^{1}$ and Jun $\mathrm{Hu} \mathbb{1}^{2}$ \\ ${ }^{1}$ School of Civil Engineering, Shaoxing University, Shaoxing, Zhejiang 312000, China \\ ${ }^{2}$ College of Civil Engineering and Architecture, Hainan University, Haikou 570228, China
}

Correspondence should be addressed to Jun Hu; hj7140477@hainanu.edu.cn

Received 11 November 2020; Accepted 11 December 2020; Published 24 December 2020

Academic Editor: Jian Xu

Copyright (c) 2020 Wei Wang et al. This is an open access article distributed under the Creative Commons Attribution License, which permits unrestricted use, distribution, and reproduction in any medium, provided the original work is properly cited.

Calcareous sand is characterized by low strength, multiporosity, and high-pressure shrinkage. This often leads to poor engineering properties. Therefore, it is often necessary to reinforce the calcareous sand in order to meet the actual engineering demand for bearing capacity. To study the modification effect of calcareous sand of nanoclay by cement, mechanical tests and microscopic tests of the cement calcareous sand (CCS) modified by different nanoclay content and cement content were conducted. Through the unconfined compressive test, the mechanical properties of nanoclay and cement compound modified calcareous sand (NCCS) were studied. The micromechanism of nanoclay and cement composite modified calcareous sand was analyzed by SEM. Representative curves of data groups of stress and strain data were obtained by the fusion algorithm, which effectively circumvented the discrete distribution of determined data. Test results showed that the following: (1) The compressive property of CCS could be improved by the admixture of nanoclay, and the optimum admixture ratio was $8 \%$. (2) The admixture of nanoclay could enhance the deformation modulus of CCS and improve the resistance of CCS against external load deformation capacity. (3) Nanoclay could increase the density of the internal structure of CCS and improve its mechanical properties.

\section{Introduction}

In the category of rock soil, calcareous sand belonged to carbonate soil or calcareous soil, which was mainly composed of bone fragments of sea organism skeleton under the impact of sea water, such as cay, seaweed, shell, and so on [1-3]. Because calcareous sand did not undergo long distance transportation during the sedimentation [4], there were lots of small pores in sand particles with irregular shapes and sharp edges and corners.

In the 1960s, the unfavorable effect of calcareous sand gradually occurred in practical engineering [5]. The pile sliding of the petroleum platform in Iran did not cause an unfavorable effect on practical engineering. Thus, the engineering problem caused by calcareous sand did not draw great attention. Until the 1970s, with the surging number of the petroleum crisis, the engineering problem caused by the calcareous sand gradually draw attention [6]. Thus, researchers at home and abroad began to study the basic engineering property of calcareous sand [7-9]. Zhang et al. [10] studied the mechanical properties of calcareous sand through a drained triaxial test. The results showed that the dilation phenomenon was obvious and the particle breakage index was the smallest under the same consolidation pressure. Shen et al. [11] showed that the particle morphology of calcareous sand was irregular and multiangle. Changing the coarse particle content was the most effective way to decrease the compressibility of calcareous sand. Rasouli et al. [12] showed that not only the shear strength but also the plastic deformation of calcareous sand was larger than those of quartz sands. Many researches [13-15] showed that calcareous sand still has the characteristics of low strength, easy breakage, and high compressibility in practical engineering. To prepare the calcareous sand for further usage in the construction of superstructures, necessary stabilization is required $[11,16]$. Cement, as a common gelatinizing agent, can greatly improve the mechanical properties of soft soil. Liu et al. $[17,18]$ studied the effect of 
the concentration of gelatinizing agent on the deep cemented soil strength and further discussed the thermal conductivity property of cemented rock soil engineering material. Wang et al. $[19,20]$ found that cement performed better than lime when improving the unconfined compressive strength of dredged marine clay. Thus, part of the researchers began to study the mechanical properties of cement solidified calcareous sand. Sharma and Fahey [21] demonstrated that cement could enhance the shear strength of calcareous sand. Ismail et al. [22] studied the influence of different cementation materials on the mechanical properties of calcareous sand through a triaxial test. The results demonstrated that compared with calcite in powder and pulverized lime, Portland cement could form better cementation of calcareous sand. Thus, in this work, cement was chosen as the gelatinizing agent of calcareous sand.

Nanotechnology and nanomaterial had a broad research prospect in the $21^{\text {st }}$ century $[23,24]$. Yao et al. $[25,26]$ explored the influence of nano-MgO on the strength of cement silty clay through a direct shear test. The results demonstrated that the appropriate admixture of nano- $\mathrm{MgO}$ could improve the mechanical performance of cement silty clay. Wang et al. [27] found that nano-MgO can modify the shear properties of cement silty clay through a direct shear test, and the optimal mixing ratio was $5 \%$. Nanoclay was one of the common nanomaterials which could be widely applied in the cemented materials. Allalou et al. [28] demonstrated that nanoclay could be used as a catalyst to promote the cement hydration reaction of low clinker cement mortar. Mohamed et al. [29] obtained a similar conclusion. Li et al. [30] found that the substitution of 5\%-10\% nanoclay for cement could enhance the compressibility of cement iron tailings through an unconfined compression test. Zaid et al. [31] demonstrated that the solidifying effect of soft soil by the admixture of nanoclay was the best through a triaxial test. Irshidat et al. [32] explored the influence of nanoclay on the mechanical properties of modified cement-based materials. The results showed that the bending strength was the best with the $2 \%$ admixture of nanoclay at $400^{\circ} \mathrm{C}$. The above researches showed that nanoclay could improve the mechanical performance of cemented material.

In sum, although there were lots of studies at home and abroad about the mechanical performance of calcareous sand, the studies about the mechanical performance of the nanomaterial modified calcareous sand were few. In this work, the influence of the nanoclay admixture on the compressive strength of cement solidifying calcareous sand was mainly studied. The resistance against external load deformation capacity of the nanoclay modified cement calcareous sand was studied, which was anticipated to provide a reference for the usage of nanoclay and cement compound modified calcareous sand in the job site.

\section{Experimental Materials and Preparation}

2.1. Experimental Materials. Calcareous sand in this work was from one district of Yongxing Island, Sansha City, Hainan Province, which was loose and noncemented sand particle. The particle size distribution curve is shown in Figure 1. Compared

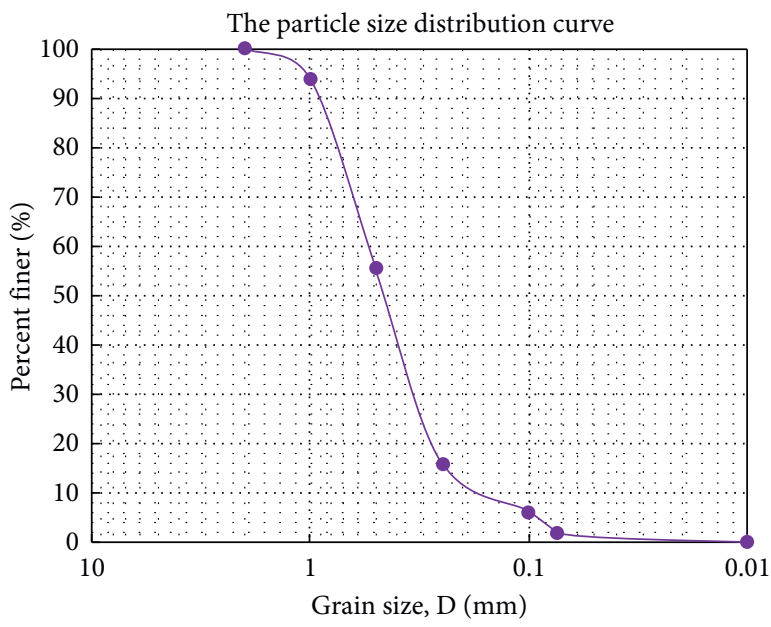

FIgURE 1: The particle size distribution curve in this experiment.

with common terrestrial sand, calcareous sand was pale. There were coral fragments in calcareous sand. Thus, there were some red particles in white sand particles. The basic physical mechanical indexes of calcareous sand are shown in Table 1.

In this experiment, common Lanting PO 32.5 Portland cement produced by Zhaoshan Architectural Limited Co. in Shaoxing City was used, whose basic physical mechanical indexes are shown in Table 2.

Nanoclay which was a light yellow powder was produced by Jingxi Montmorillonite Technology Limited Co. in Hubei, whose main technical indexes are shown in Table 3.

The microstructure of calcareous sand, cement, and nanoclay is shown in Figure 2. As could be seen from Figure 2(a), there were many pores on the surface of the microstructure of calcareous sand, which indicated that calcareous sand has high compression properties and is easy to be broken. As could be seen from Figure 2(b), the size of cement particles was different and the edges and corners were clear. As could be seen from Figure 2(c), the microstructure of nanoclay was relatively dense and the particle size was small, which indicated that it has a good size effect.

\subsection{Experiment Preparation}

2.2.1. Experiment Instrument. The unconfined compressive test used 01-LH0501 automated, multifunctional unconfined compressive machine, which was produced by Nanjing TaikeAo Scientific Limited Co., as shown in Figure 3. In this experiment, the load rate of the calcareous sand sample was set as $1 \mathrm{~mm} / \mathrm{min}$.

2.3. Experiment Scheme. The experiment considered the influence of not only the admixture of nanoclay but also the curing time on cement calcareous sand. The average natural moisture content of calcareous sand used in the test was 30\%. Combined with "design specification for cement soil mix proportion" [33] (JGJ 233-2011) and practical engineering application, the mixing ratio of cement was $10 \%$. In the experiment, with controlled cement content and the water 
TABLE 1: The basic physical mechanical parameters of calcareous sand in one district of Sansha City.

\begin{tabular}{lcccccc}
\hline $\begin{array}{l}\text { The depth of } \\
\text { the sand layer } \\
(\mathrm{m})\end{array}$ & $\begin{array}{c}\text { Gravity } \gamma \\
\left(\mathrm{kN} \cdot \mathrm{m}^{-3}\right)\end{array}$ & $\begin{array}{c}\text { The standard value } \\
\text { of cohesive force c } \\
(\mathrm{kPa})\end{array}$ & $\begin{array}{c}\text { The standard value of } \\
\text { internal friction angle } \\
\Phi\left(^{\circ}\right)\end{array}$ & $\begin{array}{c}\text { Compressive } \\
\text { modulus E }(\mathrm{MPa})\end{array}$ & $\begin{array}{c}\text { Permeability } \\
\text { coefficient K } \\
\left(\mathrm{cm} \cdot \mathrm{s}^{-1}\right)\end{array}$ & $\begin{array}{c}\text { Eigenvalue of } \\
\text { bearing capacity f } \mathrm{fak}_{\mathrm{ak}} \\
(\mathrm{kPa})\end{array}$ \\
\hline $25-30$ & 18 & 5 & 30 & 10 & $8.0 \times 10^{-2}$ & 200 \\
\hline
\end{tabular}

TABLE 2: Basic physical mechanical indexes of Lanting cement.

\begin{tabular}{|c|c|c|c|c|c|c|c|c|}
\hline \multirow[t]{2}{*}{ Fineness (\%) } & \multirow[t]{2}{*}{$\begin{array}{l}\text { The time of initial } \\
\text { cementation ( } \mathrm{min} \text { ) }\end{array}$} & \multirow[t]{2}{*}{$\begin{array}{l}\text { The time of final } \\
\text { cementation ( } \mathrm{min})\end{array}$} & \multirow[t]{2}{*}{$\begin{array}{c}\text { The stability boiling } \\
\text { method }\end{array}$} & \multirow[t]{2}{*}{$\begin{array}{c}\text { The burning loss } \\
\text { amount } \%\end{array}$} & \multicolumn{2}{|c|}{$\begin{array}{c}\text { The } \\
\text { compressive } \\
\text { strength } \\
(\mathrm{MPa})\end{array}$} & \multicolumn{2}{|c|}{$\begin{array}{l}\text { The } \\
\text { rupture } \\
\text { strength } \\
(\mathrm{MPa})\end{array}$} \\
\hline & & & & & $3 \mathrm{~d}$ & $28 \mathrm{~d}$ & $3 \mathrm{~d}$ & $28 \mathrm{~d}$ \\
\hline 3.4 & 210 & 295 & Qualified & 1.4 & 26.9 & 48.1 & 4.9 & 9.0 \\
\hline
\end{tabular}

TABLE 3: The technical parameters of nanoclay.

\begin{tabular}{lcccccc}
\hline Project & Composition & Appearance & $\begin{array}{c}\text { Montmorillonite } \\
\text { content }(\%)\end{array}$ & $\begin{array}{c}\text { Apparent } \rho \\
\left(\mathrm{g} / \mathrm{cm}^{3}\right)\end{array}$ & $\begin{array}{c}\text { Diameter/thickness } \\
\text { thickness } \\
(\mathrm{nm})\end{array}$ & $\begin{array}{c}\text { The moisture } \\
\text { content }(\%)\end{array}$ \\
\hline $\begin{array}{l}\text { Technical } \\
\text { indexes }\end{array}$ & $\begin{array}{c}\text { Montmorillonite } \\
\text { derivatives }\end{array}$ & $\begin{array}{c}\text { Light yellow } \\
\text { powder }\end{array}$ & $96-98$ & 0.45 & 200 & $\leq 25$ \\
\hline
\end{tabular}

content, the influence of nanoclay admixture and the curing time $(7 \mathrm{~d}, 14 \mathrm{~d}$, and $28 \mathrm{~d}$ ) on the unconfined compressive strength of calcareous sand were studied. The experimental design scheme is shown in Table 4. According to the Geotechnical test standard of GBT 50123-2019 [34], not until $3-5 \%$ strain after the peak in the unconfined test did the test end. In this work, not until 5\% axial strain did the test end.

2.4. Sample Preparation and Curing. According to the Geotechnical test standard of GBT 50123-2019 [34], in this experiment, unconfined samples were all cylinders with a diameter of $39.1 \mathrm{~mm}$ and a height of $80 \mathrm{~mm}$. The detailed calcareous sand sample preparation procedures were as follows:

(1) Calcareous Sand Preparation. Before experiments, the air-dried calcareous sand was oven-dried at the temperature of $105^{\circ} \mathrm{C}$. Impurities of little shells and cay fragments in calcareous sand were removed by $2 \mathrm{~mm}$ sieve. The residuals were saved in air-tight storage box as shown in Figure 4(a).

(2) Sample Molds Preparation. Sample molds were washed and oven-dried, whose inner wall was then coated with Vaseline evenly. Then, it was assembled as shown in Figure 4(b).

(3) Sand Mixture Preparation. Materials were weighed according to the designed weight in the experiment. Then cement and nanoclay were put into calcareous sand in the stirring pot, which was stirred in the mechanical mixing apparatus. During mixing, water was slowly put into the stirring pot. The mechanical mixing time was $10 \mathrm{~min}$. It was shown in Figure 4(c).

(4) Molding of the Calcareous Sand Sample. The lower part of the sample mold was wrapped by preservative film and set on the base of compaction. Subsequently, calcareous sand was compacted by four layers using the instrument. The compaction tools for calcareous sand samples are shown in Figure 4(d). $41 \mathrm{~g}$ calcareous sand was weighed each time and put into three valves through the funnel. After each impact, the surface of the calcareous sand sample was made coarse to guarantee the intact of the sample.

(5) The Sample Curing and Mold Removal. When finishing of the calcareous sand sample, it was necessary to smooth the sample surface. Then the sample was put into the saturated apparatus of the sample mold. Taps of the curing time and the admixture amount were labeled and as shown in Figure 4(e). More importantly, drip stones were put at two ends of the sample. The filtration paper was put between the drip stone and the sample to prevent the calcareous sand particle from adhering to the drip stone. Due to the characteristic of the loose property and low cohesion, the calcareous sample was needed to be cured for $4 \mathrm{~d}$ with mold, which was removed subsequently. After mold was removed, the sample was wrapped by preservative film and cured in the curing room. The molded calcareous sample was shown in Figure 4(f).

\section{Unconfined Compressive Experiment}

3.1. Stress-Strain Curves. To study the influence of nanoclay content and curing time on the mechanical performance of cement calcareous sand, the unconfined compressive experiment was conducted in this work. The stress-strain curves of CCS and NCCS samples on $7 \mathrm{~d}, 14 \mathrm{~d}$, and $28 \mathrm{~d}$ are shown in Figures 5-7, respectively, among which nos. 1-5 represented test curves of five parallel samples.

Combined with Figures 5-7, the stress-strain curves of unconfined experiments of CCS and NCCS were both softening curves. To circumvent the deviation from the peak 


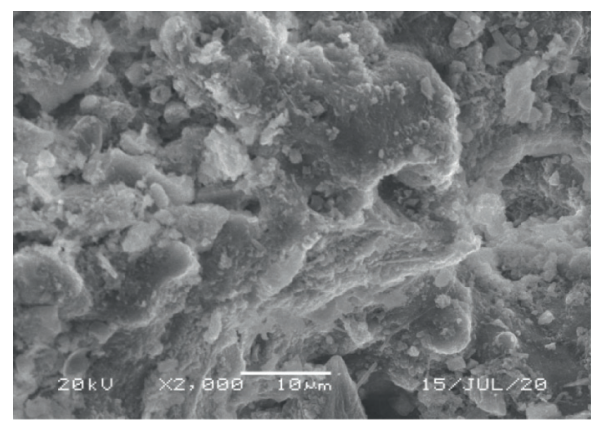

(a)

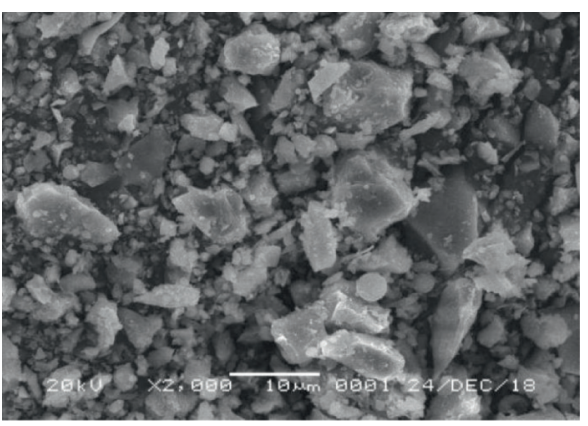

(b)

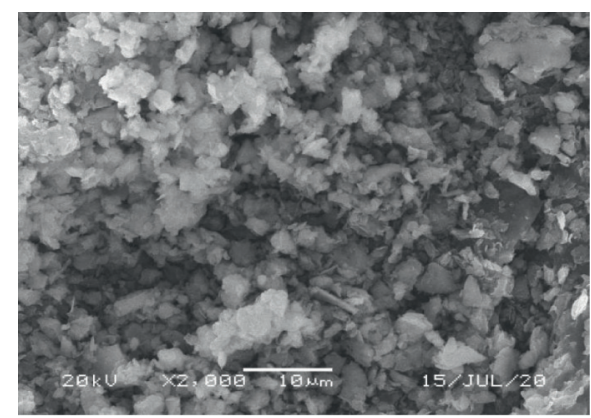

(c)

Figure 2: Microstructures of (a) calcareous sand, (b) cement, and (c) nanoclay.

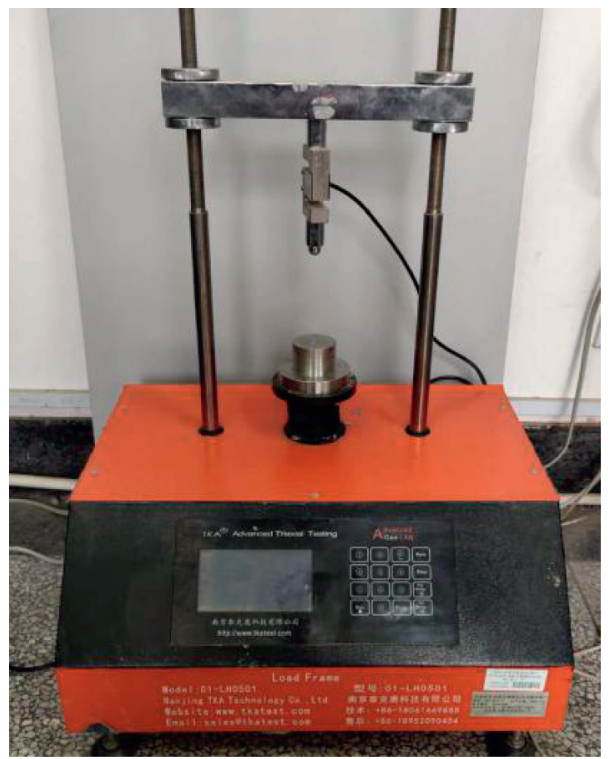

FIgURE 3: The unconfined compressive strength test machine.

value brought in by the single test, 5 repeated tests were conducted. However, 5 repeated tests were independent, which resulted in some deviation of the data. The certain discrete results could not realize the consistency. To facilitate the further analysis of the influence of nanoclay admixture and curing time on the compressibility of cement calcareous sand, it was very important to integrate 5 stress-strain curves in the test to one curve. Combined with related references [35], the test curves were treated by normalization in this work. The detailed method procedures were as follows: 
(1) The stress deviation was confirmed. $q_{i}$ and $q_{j}(i, j=1$, $2,3,4,5)$ represented the corresponding peak stress of five groups of unconfined tests, respectively. $r_{i j}$ represented the absolute value of the difference between the stress of $q_{i}$ and $q_{j}$, respectively. The calculation was shown in the following equation:

$$
r_{i j}=\left|q_{i}-q_{j}\right| .
$$

(2) The correlation degree of the stress was confirmed. $c_{i j}$ was the correlation degree of stress. The calculation method was shown in equation (2). $c_{i j}$ and the stress deviation $r_{i j}$ should be in a relationship of inverse proportion. The larger the stress deviation, the smaller $c_{i j}$. If the stress deviation $r_{i j}$ was 0 , the correlation degree $c_{i j}$ was 1 , illustrating that the correlation degree of the stress with itself was 1 :

$$
c_{i j}=1-\frac{r_{i j}}{\operatorname{Max}\left\{r_{i j}\right\}} .
$$

(3) The stress correlation degree matrix was established. In Matrix C, $c_{i j}$ represented the correlation degree between two stresses of the ith and jth as shown in equation (3). However, it could not completely demonstrate the correlation degree between one stress and all other stresses:

$$
C=\left|\begin{array}{lllll}
c_{11} & c_{12} & c_{13} & c_{14} & c_{15} \\
c_{21} & c_{22} & c_{23} & c_{24} & c_{25} \\
c_{31} & c_{32} & c_{33} & c_{34} & c_{35} \\
c_{41} & c_{42} & c_{43} & c_{44} & c_{45} \\
c_{51} & c_{52} & c_{53} & c_{54} & c_{55}
\end{array}\right| .
$$

(4) The weighing factor was confirmed. $w_{j}$ should comprehensively consider influence factors of all correlation degrees. From amalgamating theory of probability theory, there existed a group of nonnegative values of $v_{1}, v_{2}, v_{3}, v_{4}$ and $v_{5}$, which permitted the establishment of the following equation:

$$
w_{i}=v_{1} c_{i 1}+v_{2} c_{i 2}+v_{3} c_{i 3}+v_{4} c_{i 4}+v_{5} c_{i 5} .
$$

(5) The weighing matrix was established. Equation (4) was transformed to matrix as shown in equation (5). In equation (5), $W=\left[w_{1}, w_{2}, w_{3}, w_{4}, w_{5}\right]^{T}$ and $V=\left[v_{1}, v_{2}, v_{3}, v_{4}, v_{5}\right]^{T}$.

$$
W=\mathrm{CV}
$$

(6) The stress weighing coefficient was confirmed. Since the correlation degree matrix $C$ is nonnegative, there exists an eigenvalue $\lambda$, which makes the equation $\lambda V=\mathrm{CV}$ hold. Then the eigenvector $V$ can be obtained by the eigenvalue $\lambda$. The calculation method of weighing coefficient was shown in the following equation:

$$
w_{i}=\frac{\left|v_{i}\right|}{\sum_{i=1}^{n=5}\left|v_{i}\right|} .
$$

(7) The fusion stress was confirmed. $w_{i}$ was the weighing coefficient of the ith value. The fusion result of 5 stress was shown in the following equation:

$$
q_{f}=\sum_{i=1}^{n=5} q_{i} w_{i}
$$

From Figures 5-7, 5 stress-strain curves with each admixture ratio basically demonstrated a consistent changing principle. According to the above-described method, the weighing coefficient of each curve was obtained by the application of the fusion algorithm for the peak values of five stress-strain curves. The density $p$ was obtained by the comparison of the fusion stress and the stress average. The weighing coefficient calculation results of correlated curves of CCS and NCCS on $7 \mathrm{~d}, 14 \mathrm{~d}$, and $28 \mathrm{~d}$ are shown in Table 5.

To verify the feasibility, the obtained stress-strain curves were compared with the original data, which is shown in Figure 8. Results showed that the stress-strain curve obtained by the fusion algorithm had a relatively good correlation with original unconfined compressive strength data.

The weighed stress-strain cures of CCS and NCCS with a different admixture of nanoclay by fusion algorithm are shown in Figure 9. Figures 9(a)-9(c) represent those with the curing time of $7 \mathrm{~d}, 14 \mathrm{~d}$, and $28 \mathrm{~d}$, respectively.

From Figure 9, the stress-strain curves of CCS and NCCS on $7 \mathrm{~d}, 14 \mathrm{~d}$, and $28 \mathrm{~d}$ were all softening curves. The peak stress of NCCS with different ages was all larger than those of CCS, illustrating that the admixture of nanoclay could enhance the peak stress of CCS. As shown in Figure 10, the trends of stress-strain curves with different ages and different admixture contents were approximately the same, which could be approximately divided into four stages. Zone I was the precompressive stage, which corresponded to precontact between the sensor and CCS and NCCS samples. 
TABle 4: The experimental design scheme.

\begin{tabular}{lcccc}
\hline Sample & Cement content (\%) & Nanomaterial content $(\%)$ & Water content $(\%)$ & Curing time/day \\
\hline CCS-7 & 10 & 0 & 30 & 30 \\
CCS-14 & 10 & 0 & 30 & 14 \\
CCS-28 & 10 & 0 & 30 & 28 \\
NCCS-4-7 & 10 & 4 & 30 & 7 \\
NCCS-6-7 & 10 & 6 & 30 & 7 \\
NCCS-8-7 & 10 & 8 & 30 & 7 \\
NCCS-10-7 & 10 & 10 & 30 & 14 \\
NCCS-4-14 & 10 & 4 & 30 & 14 \\
NCCS-6-14 & 10 & 6 & 30 & 14 \\
NCCS-8-14 & 10 & 8 & 30 & 30 \\
NCCS-10-14 & 10 & 10 & 30 & 28 \\
NCCS-4-28 & 10 & 4 & 30 & 28 \\
NCCS-6-28 & 10 & 6 & 30 & 30 \\
NCCS-8-28 & 10 & 10 & & 28 \\
NCCS-10-28 & 10 & & & \\
\hline
\end{tabular}

The stress variation was very small. In addition, the increasing speed was slow. (2) Zone II was a linear stage where the stress increasing speed of CCS and NCCS accelerated. The corresponding stress and strain demonstrated linear increasing relationship. Under different ages, the stress increasing speed of NCCS was apparently higher than that of CCS. (3) Zone III was the elastoplastic stage where the stress increasing speed of CCS and NCCS changed from rapid to slow with occurred apparent peak stress. The peak stresses of NCCS with a different admixture of nanoclay were all larger than those of CCS. (4) Zone IV was the attenuation stage where the stress of CCS and NCCS began to attenuate with occurred sample destroy. When the axial strain of CCS reached $3 \%$, the stress curve began to slow down and approached 0 . When the axial strain of CCS reached $4 \%$, the stress curve began to slow down and approached 0 .

\subsection{Influence of the Nanoclay Admixture on the Compressive} Strength. To facilitate the analysis of the compressibility modification effect of nanoclay and cement modified calcareous sand, the maximum of axial stress was chosen as the unconfined compressive strength of NCCS in this work. The relationship curve between the nanoclay admixture ratio and the NCCS compressive strength is shown in Figure 11.

From Figure 11, the admixture of nanoclay could enhance the compressive strength of cement calcareous sand. With the curing time of $7 \mathrm{~d}$ and with the increase of nanocaly content, the compressive strength of NCCS increased accordingly. Compared with the compressive strength of CCS $(858.97 \mathrm{kPa})$, the compressive strength of NCCS-4, NCCS-6, NCCS-8, and NCCS-10 increased $10.8 \%, 17.7 \%, 43.9 \%$, and $46.4 \%$, respectively. When the nanoclay content was between 0 and $8 \%$, the increasing speed of the compressive strength of NCCS increased gradually. When the nanoclay content exceeded $8 \%$, the increasing speed of NCCS compressive strength slowed down, illustrating that the appropriate admixture of nanoclay could enhance the CCS compressive strength. However, when the nanoclay content exceeded a certain limit, the good modified effect was not guaranteed. For example, in this experiment, the increasing amplitude of CCS compressive strength of NCCS-10 compared with that of CCS was only a little higher than that of NCCS- 8 . When the curing time was $14 \mathrm{~d}$ and $28 \mathrm{~d}$, with the increase of nanoclay content, the compressive strength of NCCS demonstrated a trend of initially increasing and then decreasing and a maximum occurred with the nanoclay content of $8 \%$. On $14 \mathrm{~d}$, the compressive strength of NCCS-4, NCCS-6, NCCS-8, and NCCS-10 increased $14.1 \%, 31.3 \%, 64.4 \%$, and $60.5 \%$, respectively, compared with that of CCS. On $28 \mathrm{~d}$, the compressive strength of NCCS-4, NCCS-6, NCCS-8, and NCCS-10 increased $26.7 \%, 66.3 \%, 77.6 \%$, and $69.7 \%$, respectively, compared with CCS.

From the above conclusions, in samples on the short ages of $7 \mathrm{~d}$, the compressive strength of NCCS increased with the increase of nanoclay content. In samples on the middle/long age of $14 / 28 \mathrm{~d}$, the compressive strength of NCCS demonstrated a trend of initial increasing and then decreasing with the increase of nanoclay content. The reason might be as follow: nanoclay in this experiment was nanoderivative of montmorillonite with hydrophilicity and weak expansibility. With low nanoclay content, water in the interior of the sample was sufficient. On the one hand, nanoclay adsorbed water swelled and filled in the internal pore of NCCS. On the other hand, the nucleation effect of nanoclay could promote the cement hydration reaction of NCCS [35]. With too high nanoclay content, hydroscopicity of nanoclay could consume the internal water of NCCS and thus prohibit the cement hydration reaction in the interior of NCCS, illustrating that there existed an optimum admixture content when modifying the CCS compressive strength by nanoclay. In this experiment, comprehensively considering factors of economy and curing time, the optimum admixture content for the modification of the CCS compressive strength by nanoclay was $8 \%$.

\subsection{Influence of the Curing Time on the Compressive Strength.} It can also be seen from Figure 11, with the increase of the curing time, the compressive strength of CCS and NCCS increased accordingly. For CCS, the compressive strength on $14 \mathrm{~d}$ 


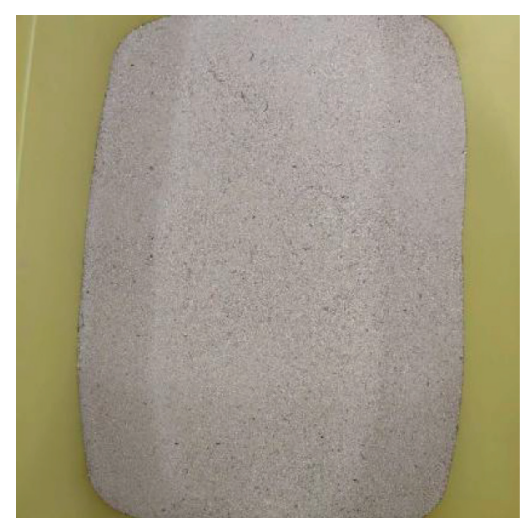

(a)

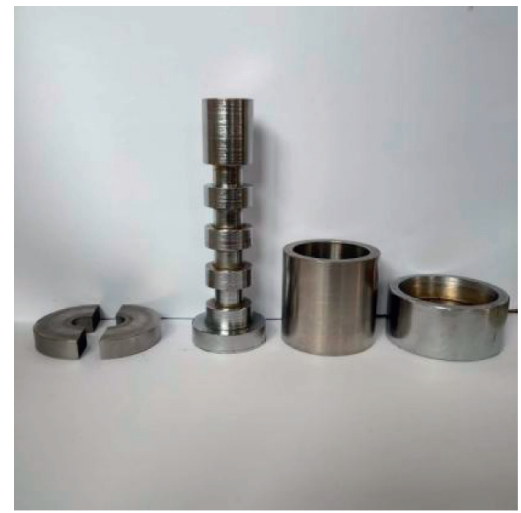

(d)

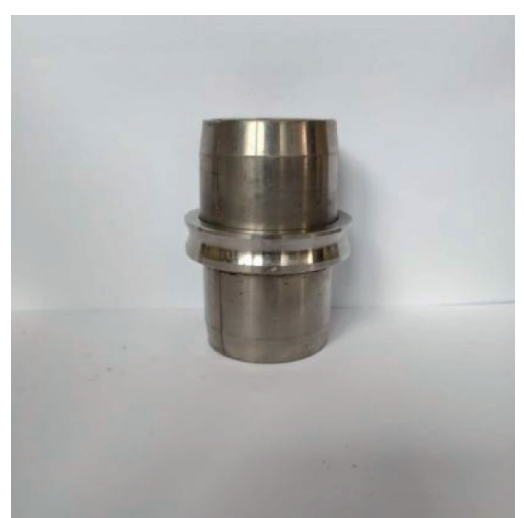

(b)

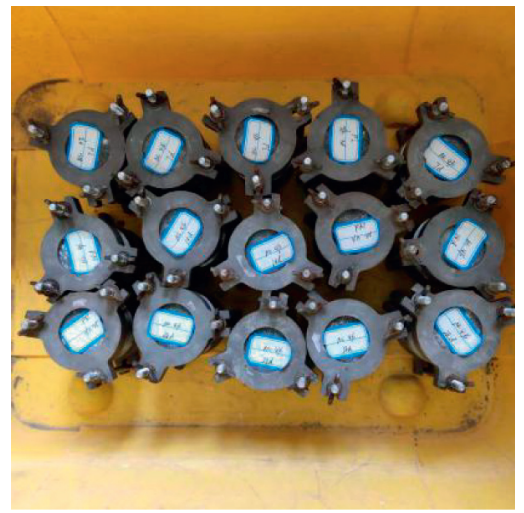

(e)

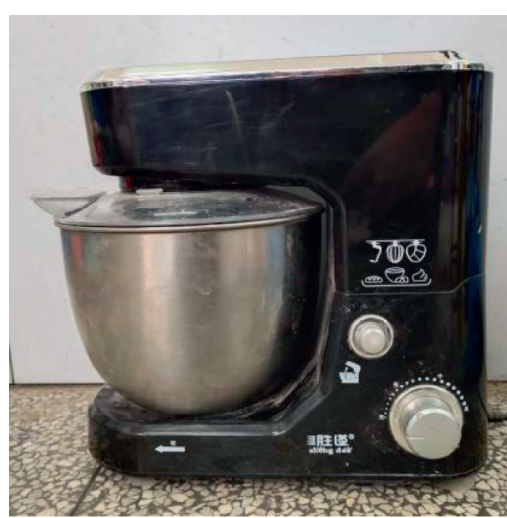

(c)

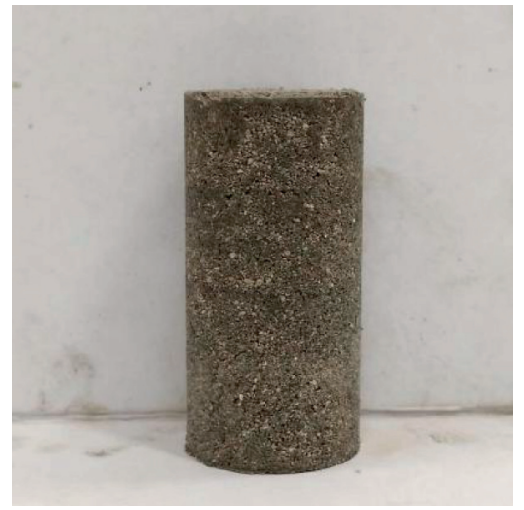

(f)

Figure 4: The manufacture flowchart of the calcareous sand sample.

and $28 \mathrm{~d}$ increased $13.1 \%$ and $37.9 \%$, respectively, compared with that on $7 \mathrm{~d}$. For NCCS, the compressive strength of NCCS4, NCCS-6, NCCS-8, and NCCS-10 on $14 \mathrm{~d}$ increased $19.6 \%$, $24.9 \%, 28.8 \%$, and $23.3 \%$, respectively, compared with that on $7 \mathrm{~d}$. On $28 \mathrm{~d}$, the compressive strength of NCCS-4, NCCS-6, NCCS-8, and NCCS-10 all increased 63.3\%, 91.9\%, 71.8\%, and $62.0 \%$, respectively, compared with that of $7 \mathrm{~d}$. Thus, the influence of the curing time on NCCS strength was greater than that on CCS, illustrating that the admixture of nanoclay to CCS could promote the cement hydration reaction of CCS. Thus, the influence of the curing time on the NCCS strength was greater than that of CCS.

3.4. NCCS Deformation Modulus Analysis. As shown in equation (8), the deformation modulus $[36,37]\left(E_{50}\right)$ was the ratio between stress and strain with $50 \%$ axial stress $q_{u}$ of soil under unconfined compressive condition. $E_{50}$ was an important parameter evaluating the compressibility, which could represent the resistance capacity against elastoplasticity deformation of soil [38]:

$$
E_{50}=50 \% \times \frac{q_{u}}{\varepsilon_{50}},
$$

wherein $q_{u}$ was the peak stress of the calcareous sand sample in the unconfined test. 50 was the axial strain with $50 \%$ of the peak stress of calcareous sand sample. According to equation
(8), the deformation modulus of NCCS was calculated and is shown in Table 6.

From Table 5, the admixture of nanoclay could effectively increase the CCS deformation modulus. With the curing time of $7 \mathrm{~d}$, the CCS deformation modulus was $70.41 \mathrm{MPa}$. Values of NCCS-4, NCCS-6, NCCS-8, and NCCS-10 increased $13.2 \%, 20.1 \%, 49.9 \%$, and $52.6 \%$, respectively, compared with that of CCS with the curing time of $7 \mathrm{~d}$. With the curing time of $14 \mathrm{~d}$, the deformation modulus of NCCS-4, NCCS-6, NCCS-8, and NCCS-10 increased $12.7 \%, 22.0 \%, 50.7 \%$, and $79.5 \%$, respectively, compared with that of CCS with the curing time of $14 \mathrm{~d}$. With the curing of $28 \mathrm{~d}$, the deformation modulus of NCCS-4, NCCS-6, NCCS-8, and NCCS-10 increased $83.8 \%, 73.1 \%, 90.4 \%$, and $76.8 \%$, respectively, compared with that of CCS with the curing time of $28 \mathrm{~d}$. The above data analysis illustrated that the nanoclay admixture could greatly improve the deformation capacity of CCS. In other words, with the same deformation requirement, NCCS could bear more external load. Khalid et al. [39] showed that there existed certain linearity between the deformation modulus and itself peak stress. The relationship between the NCCS compressive strength and the deformation modulus is shown in Figure 12. From this figure, the NCCS proportion coefficient between the deformation modulus and peak stress was between 65.87 and 99.46, namely, $E_{50}=\{65.87 \sim 99.46\} q_{u}$. By linear 

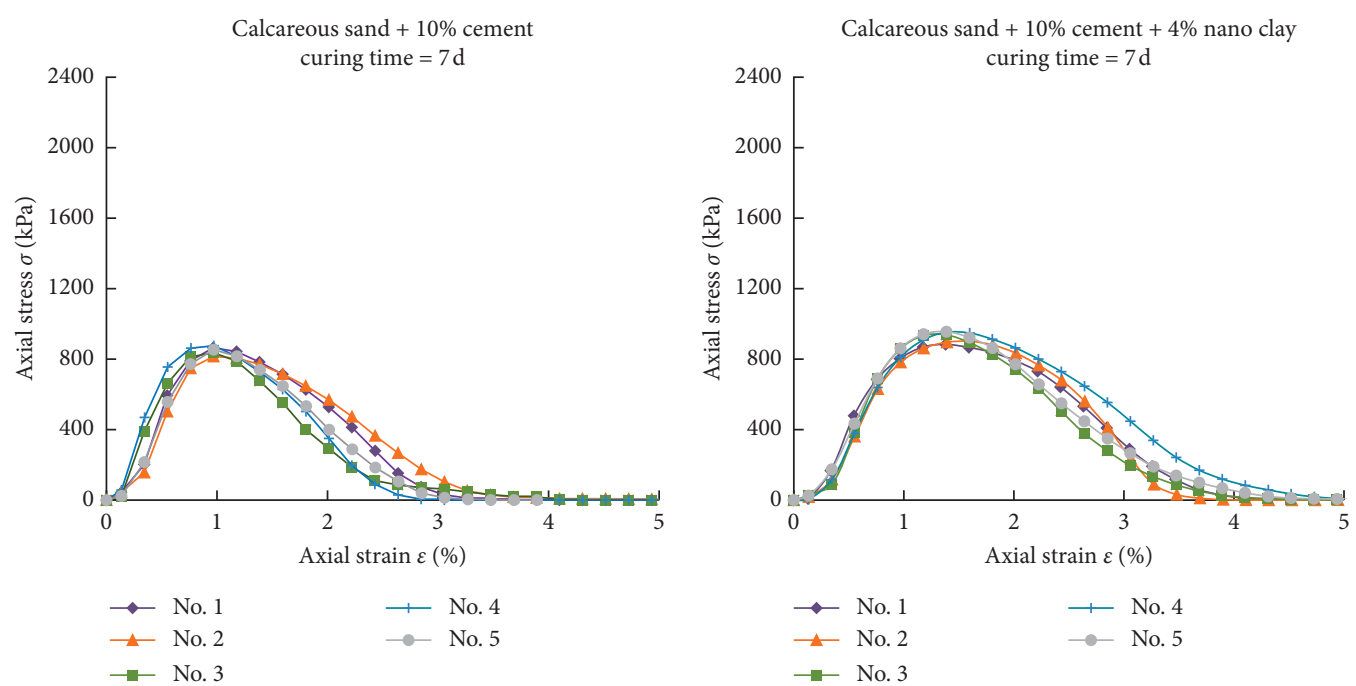

(a)

(b)
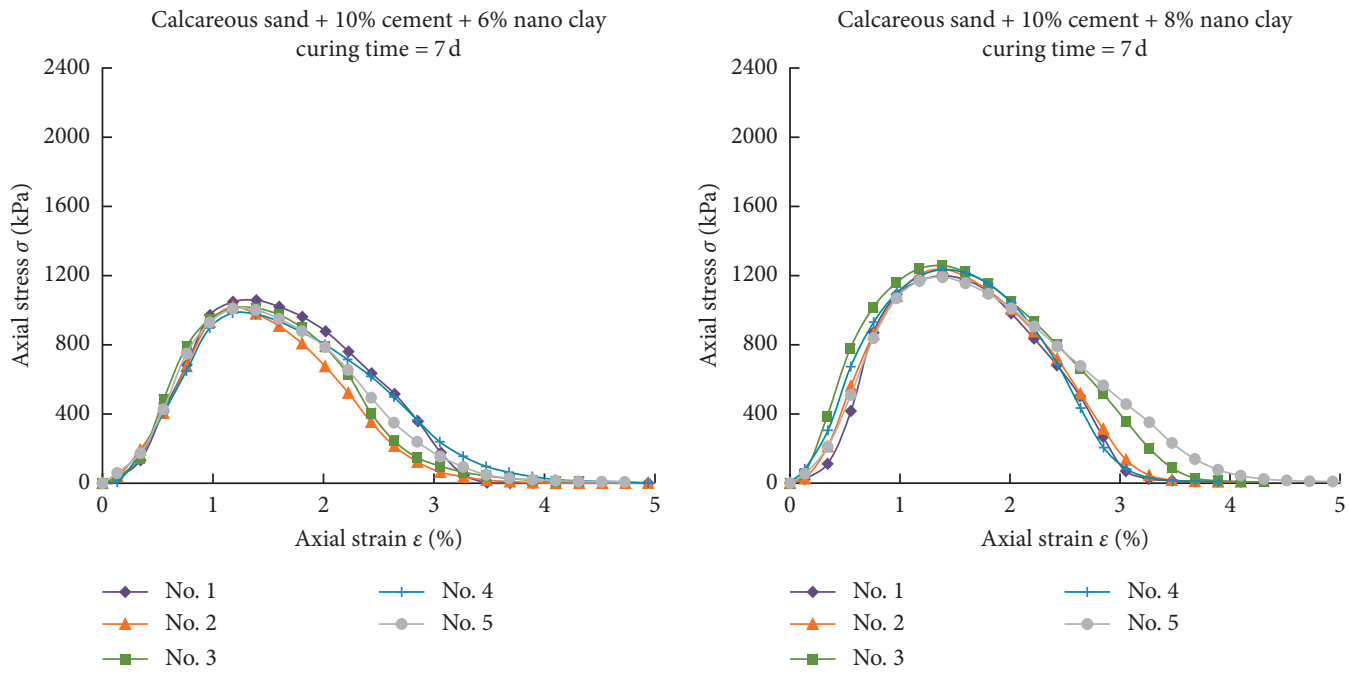

(c)

(d)

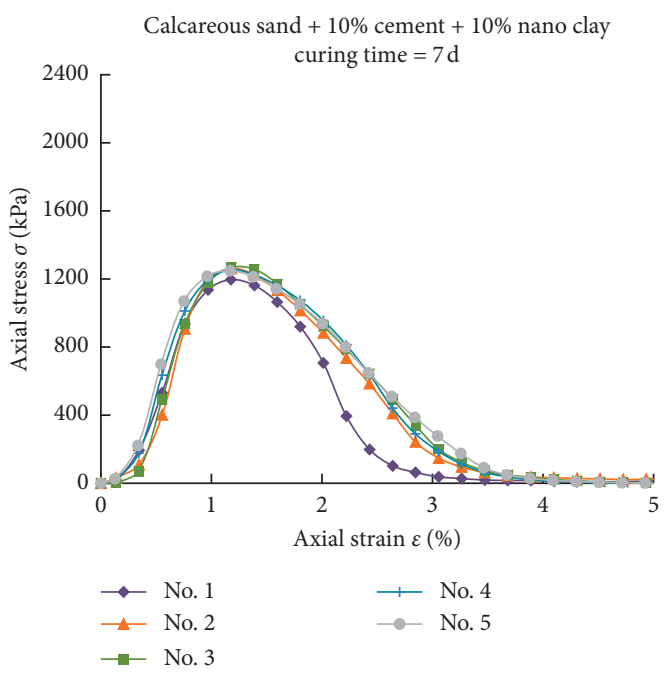

(e)

FIGURE 5: The stress-strain curves of CCS and NCCS on 7 d. (a) CCS-7. (b) NCCS-4-7. (c) NCCS-6-7. (d) NCCS-8-7. (e) NCCS-10-7. 


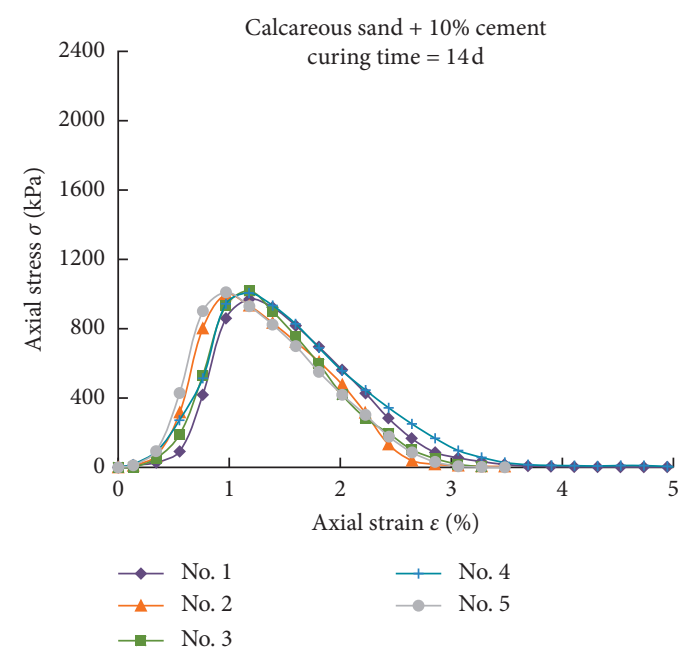

(a)

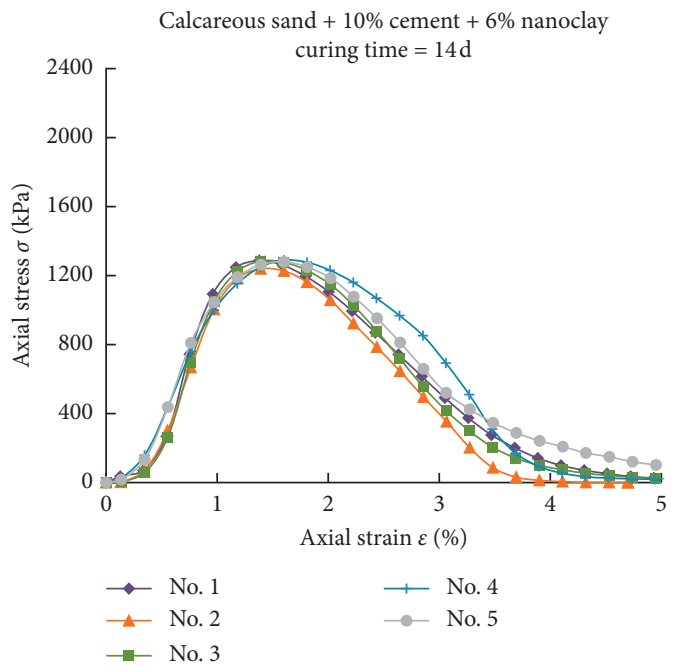

(c)

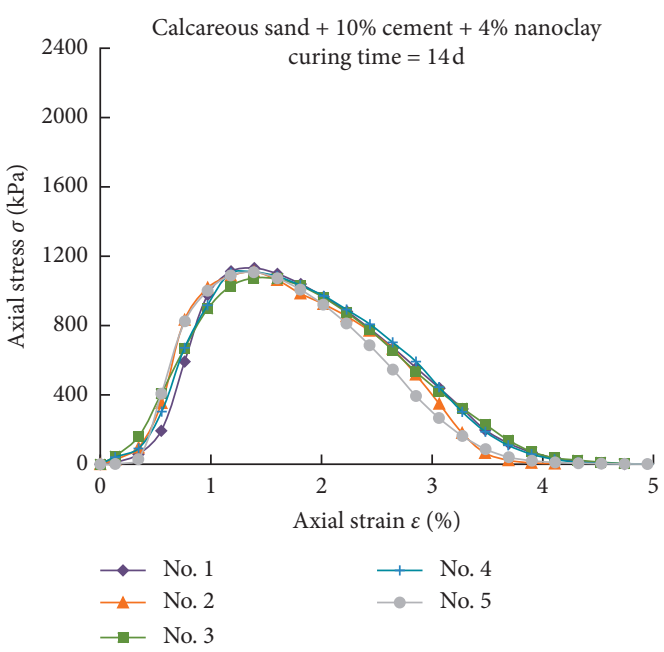

(b)

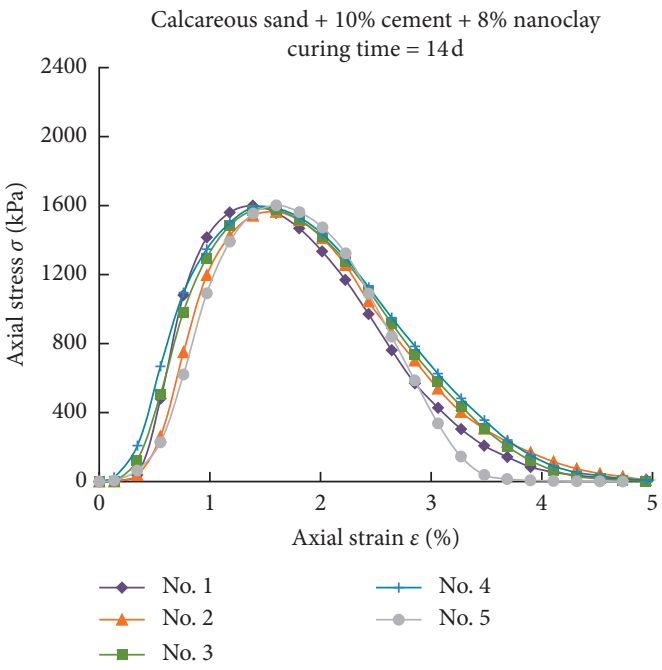

(d)

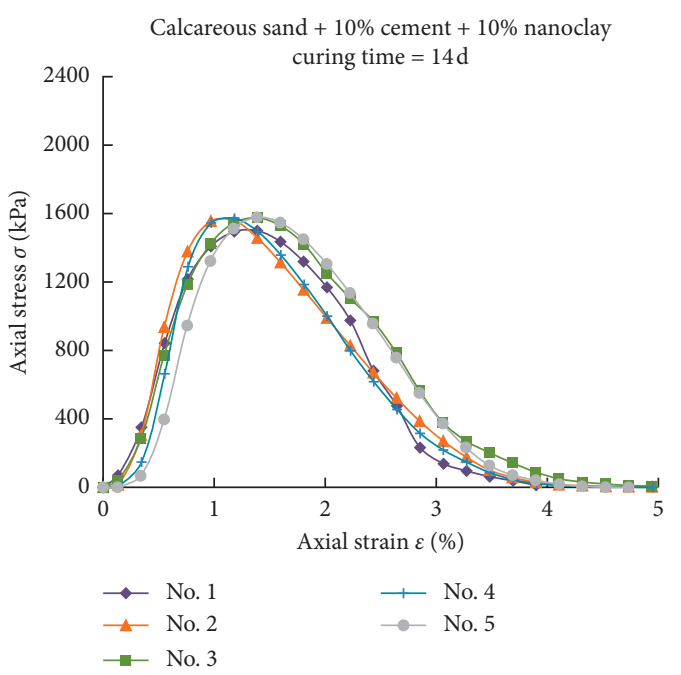

(e)

Figure 6: The stress-strain curves of CCS and NCCS on 14 d. (a) CCS-14. (b) NCCS-4-14. (c) NCCS-6-14. (d) NCCS-8-14. (e) NCCS-10-14. 


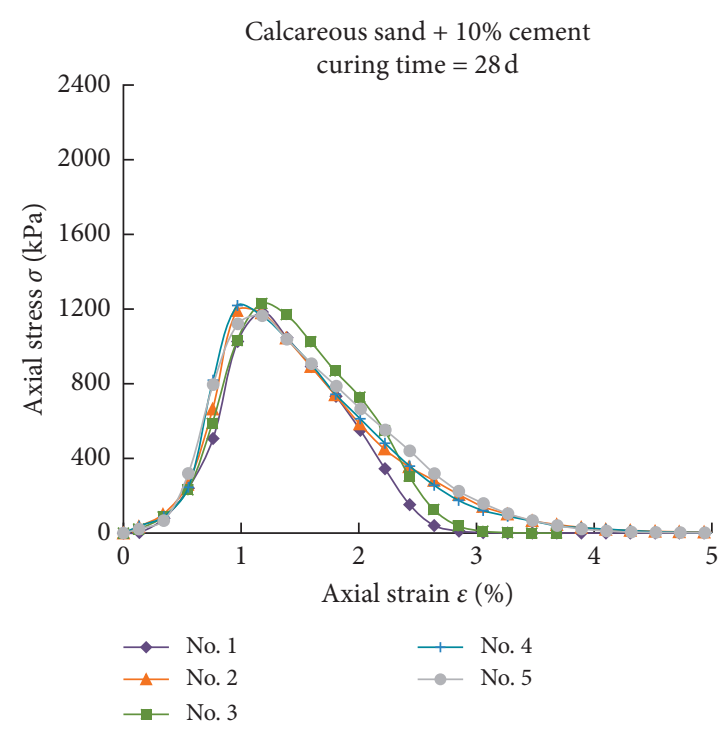

(a)

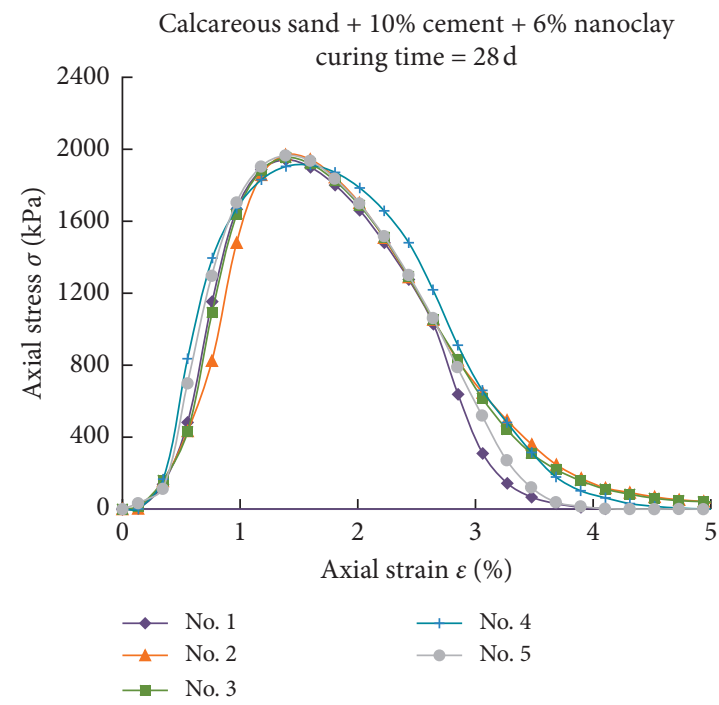

(c)

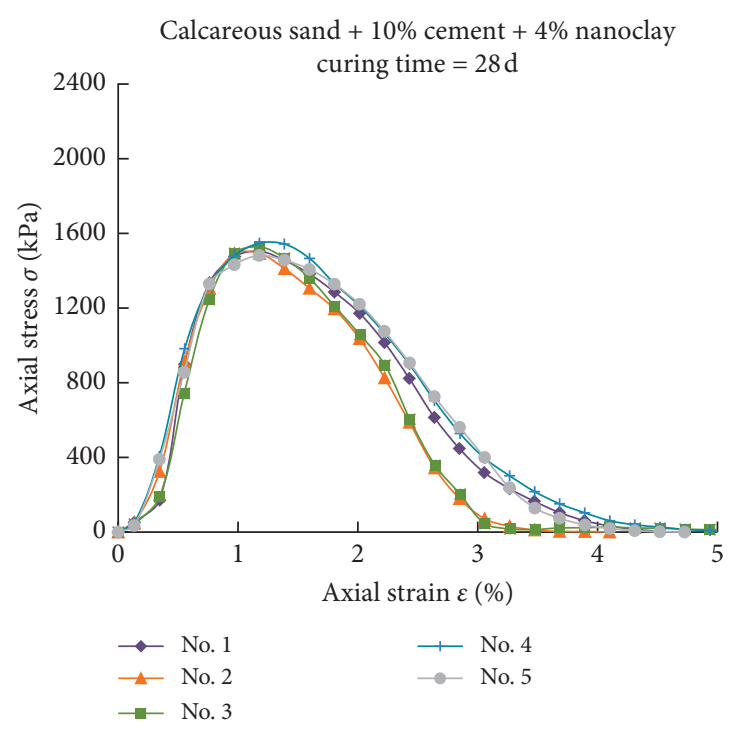

(b)

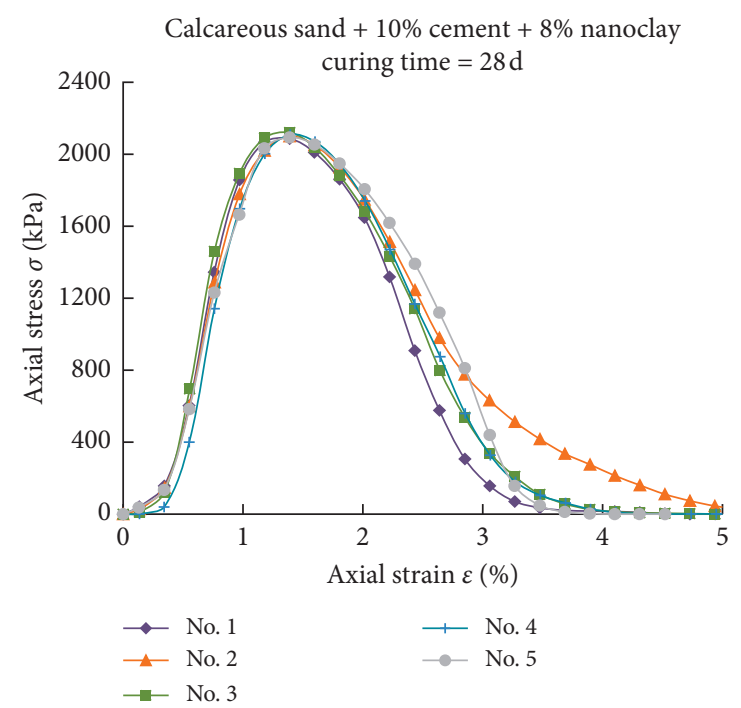

(d)

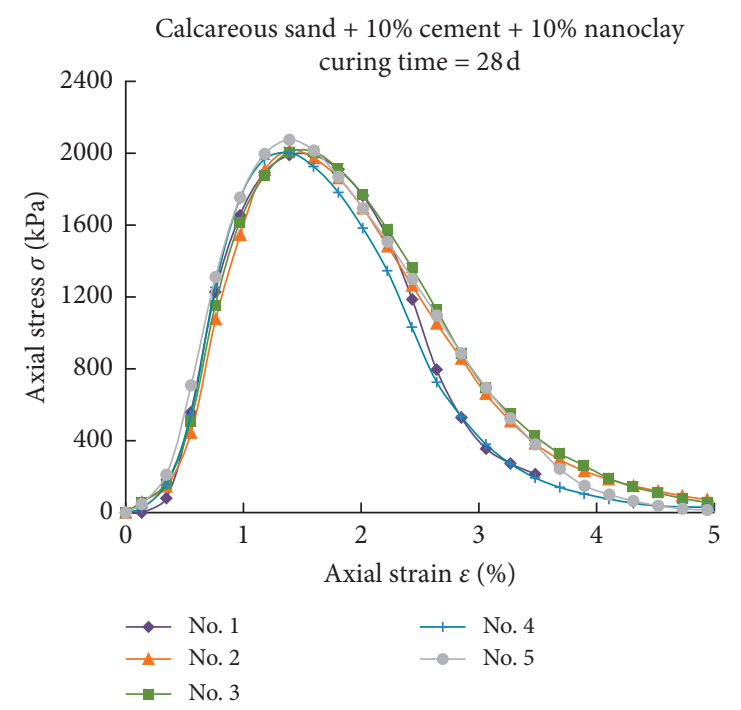

(e)

FIgUre 7: The stress-strain curves of CCS and NCCS on 28 d. (a) CCS-28. (b) NCCS-4-28. (c) NCCS-6-28. (d) NCCS-8-28. (e) NCCS-10-28. 
TABLE 5: The results of fusion algorithm.

\begin{tabular}{|c|c|c|c|c|c|c|c|c|}
\hline Age/d & No. & $\mathrm{w}_{1}$ & $\mathrm{w}_{2}$ & $\mathrm{w}_{3}$ & $\mathrm{w}_{4}$ & $\mathrm{w}_{5}$ & $q_{\mathrm{f}}(\mathrm{kPa})$ & $\mathrm{P}\left(\mathrm{q}_{\mathrm{f}} / \overline{\mathrm{q}}\right)$ \\
\hline \multirow{5}{*}{7} & CCS & 0.3874 & 0.0341 & 0.1005 & 0.1805 & 0.2976 & 858.97 & 1.0116 \\
\hline & NCCS-4 & 0.0115 & 0.0042 & 0.0576 & 0.4863 & 0.4404 & 951.91 & 1.0292 \\
\hline & NCCS-6 & 0.0065 & 0.1292 & 0.4679 & 0.0263 & 0.3701 & 1011.02 & 0.9966 \\
\hline & NCCS-8 & 0.0194 & 0.4801 & 0.0298 & 0.4668 & 0.004 & 1235.9 & 1.0098 \\
\hline & NCCS-10 & 0.0115 & 0.3134 & 0.1545 & 0.3385 & 0.1822 & 1257.38 & 1.0091 \\
\hline \multirow{5}{*}{14} & CCS & 0.0105 & 0.1175 & 0.0978 & 0.3952 & 0.379 & 969.33 & 0.9977 \\
\hline & NCCS-4 & 0.0045 & 0.3246 & 0.0016 & 0.494 & 0.1753 & 1108.98 & 1.0024 \\
\hline & NCCS-6 & 0.4422 & 0.0046 & 0.2684 & 0.2305 & 0.0543 & 1272.44 & 1.0045 \\
\hline & NCCS-8 & 0.4845 & 0.0121 & 0.0047 & 0.0482 & 0.4505 & 1593.81 & 1.0109 \\
\hline & NCCS-10 & 0.0022 & 0.442 & 0.2619 & 0.2377 & 0.0562 & 1555.43 & 1.0123 \\
\hline \multirow{5}{*}{28} & CCS & 0.3818 & 0.3607 & 0.0609 & 0.1109 & 0.0858 & 1181.33 & 0.9975 \\
\hline & NCCS-4 & 0.2329 & 0.4233 & 0.0614 & 0.0318 & 0.2505 & 1496.68 & 0.9908 \\
\hline & NCCS-6 & 0.0154 & 0.4098 & 0.0886 & 0.0134 & 0.4728 & 1965.07 & 1.0092 \\
\hline & NCCS-8 & 0.1603 & 0.3122 & 0.0391 & 0.1175 & 0.3709 & 2097.41 & 0.9978 \\
\hline & NCCS-10 & 0.0843 & 0.1543 & 0.4089 & 0.3431 & 0.0094 & 2004.21 & 0.9930 \\
\hline
\end{tabular}

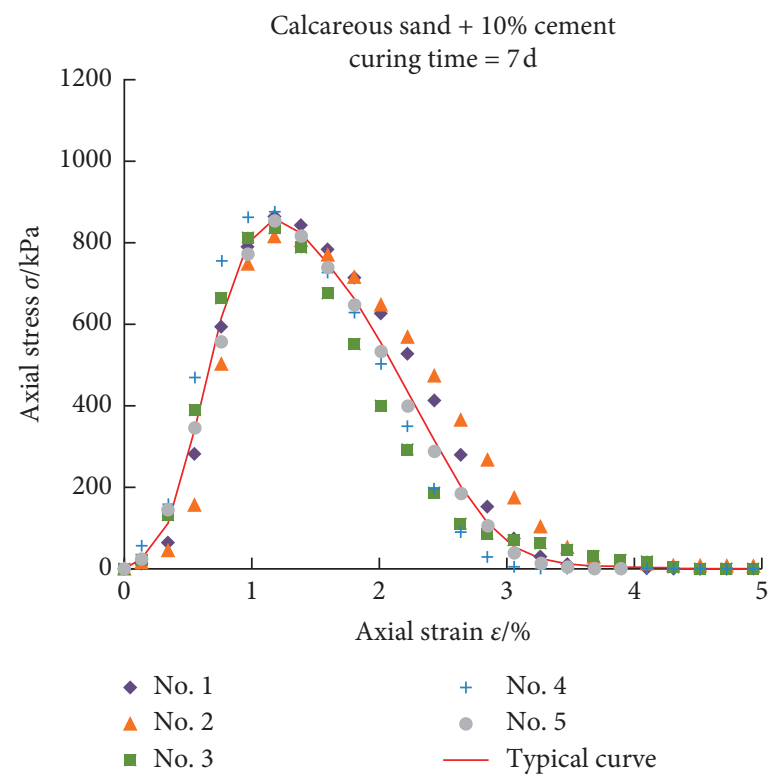

FIgURE 8: The stress-strain curves after CCS treatment.

simulation of the data point in the figure, $E_{50}=77.11 q_{u}$ with a simulation precision $R^{2}=0.9873$, which satisfied the precision requirement, providing a certain theoretical basis for the design of practical engineering.

\section{Failure Pattern of Samples}

To deeply study the information of nanoclay admixture on CCS destroyed form, in this work, the NCCS sample destroyed form was analyzed. The destroying mode of CCS and NCCS samples are shown in Figure 13. In the test process, there existed little difference between destroying modes of specimens with different curing ages. Therefore, the destroying modes of CCS and NCCS on $28 \mathrm{~d}$ were analyzed. Here only representative destroying pictures of
CCS and NCCS samples were chosen. From Figure 13, on the whole, the destroying modes of CCS and NCCS were inclined crack failure. From Figure 13(a), the destroying mode of CCS was a large tilted fracture that crossed from the upper to the lower base side with few branches of fracture. There was no apparent dropping of a calcareous sand particle in the compressive process of CCS. From Figures 13(b)-13(d), the sample fracture of NCCS was different from that of CCS. The angle of the fracture was apparently smaller than that of CCS. In addition, there were many small fractures around the main fracture. With the increase of nanoclay content, the numbers of small cracks on NCCS gradually increased. This showed that nanoclay could improve the compressive strength of CCS but increase the brittleness of CCS. 


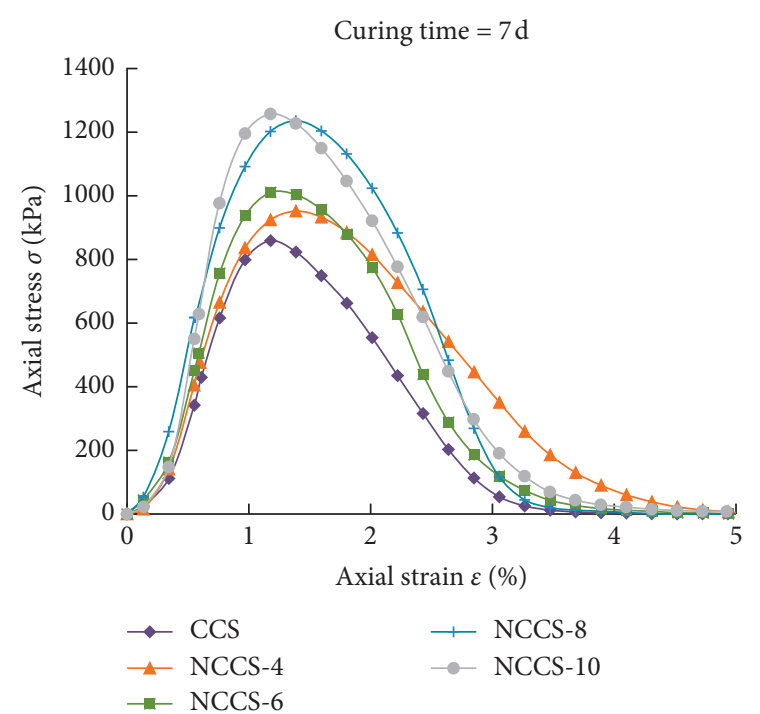

(a)

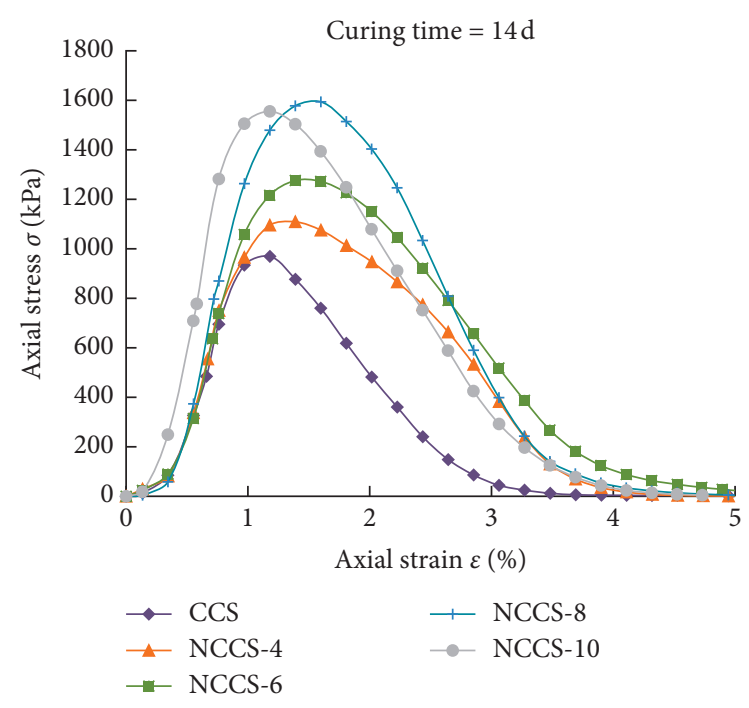

(b)

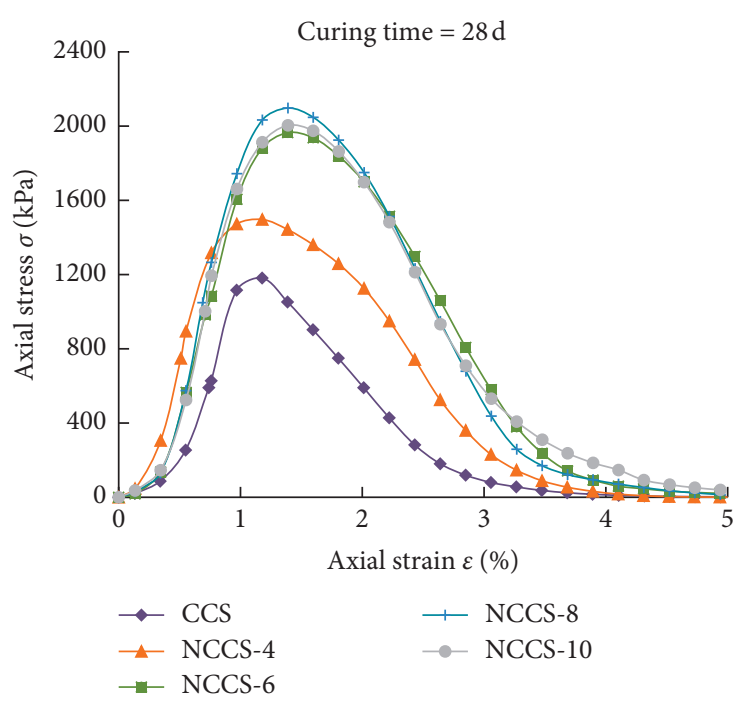

(c)

FIGURE 9: The stress-strain curves of NCCS with different admixture of nanoclay. (a) $7 \mathrm{~d}$ NCCS. (b) $14 \mathrm{~d}$ NCCS. (c) $28 \mathrm{~d}$ NCCS.

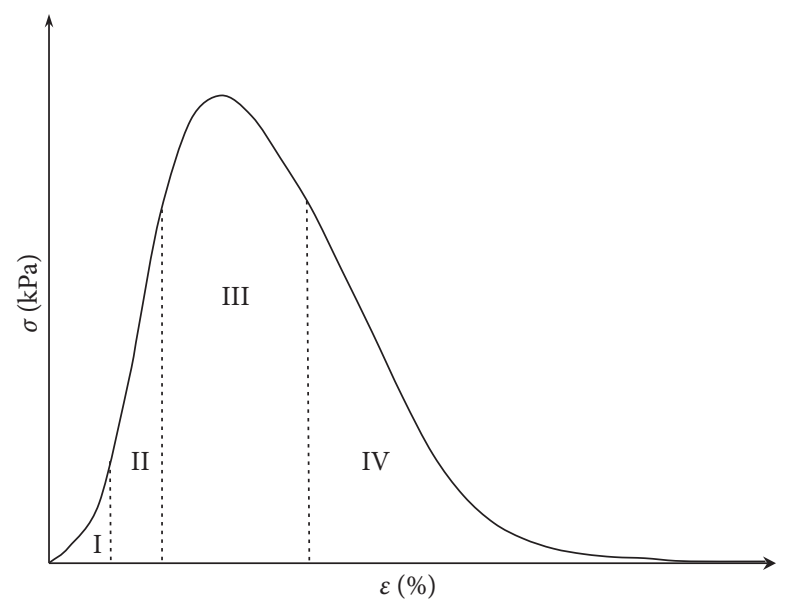

FIGURE 10: The characteristic curve of the stress-strain curve. 


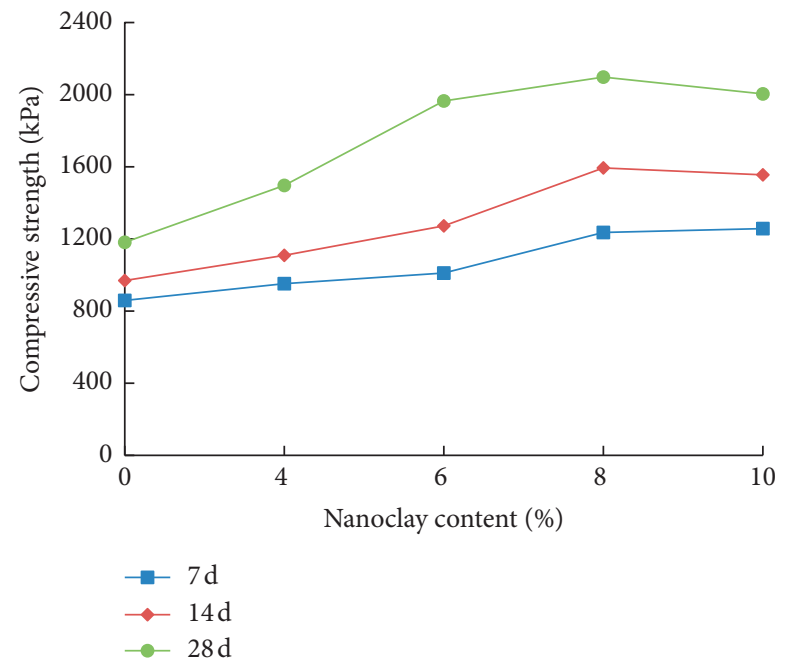

FIGURE 11: The relationship between the nanoclay content and the comprehensive strength.

TABLE 6: The calculation result of the deformation modulus of NCCS (MPa).

\begin{tabular}{lccccc}
\hline Curing time $(\mathrm{d})$ & CCS & NCCS -4 & NCCS-6 & NCCS-8 & NCCS-10 \\
\hline 7 & 70.41 & 79.33 & 85.68 & 112.35 & 106.56 \\
14 & 73.43 & 82.76 & 89.61 & 110.68 & 131.82 \\
28 & 79.82 & 146.73 & 138.19 & 151.99 & 141.14 \\
\hline
\end{tabular}

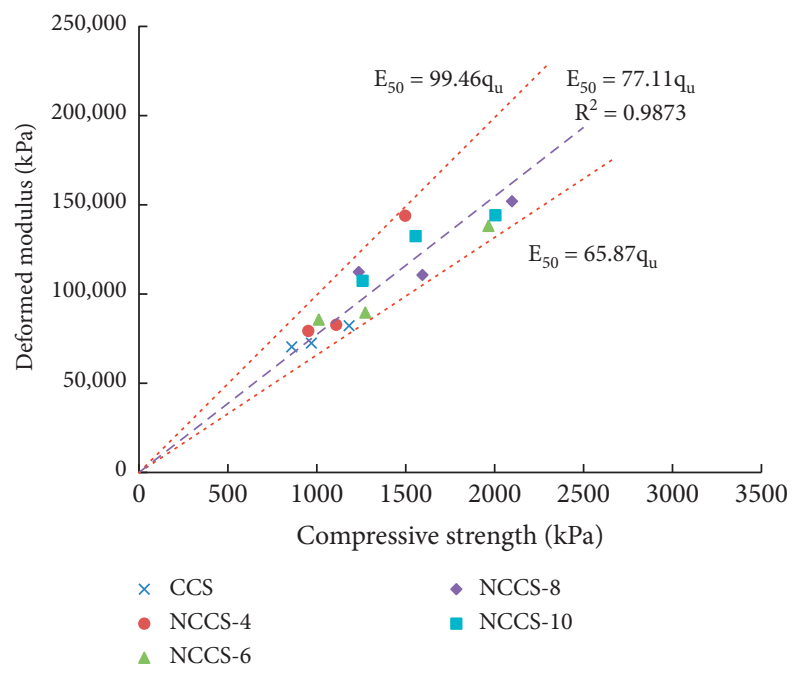

FIgURE 12: The relationship between the compressive strength and the deformed modulus.

\section{Mechanism of Modified Calcareous Sand}

In order to further analyze the mechanism of nanoclay and cement modified calcareous sand, microscopic tests were carried out on CCS and NCCS on $28 \mathrm{~d}$. The results are shown in Figure 14.
It could be seen from Figure 14(a) that the pores on the surface of calcareous sand were filled with hydration products of cement, which improved the adhesion between calcareous sand particles. It indicated that cement could better cement calcareous sand particles. It can be seen from Figure 14(b) that there were many fine nanoclay 


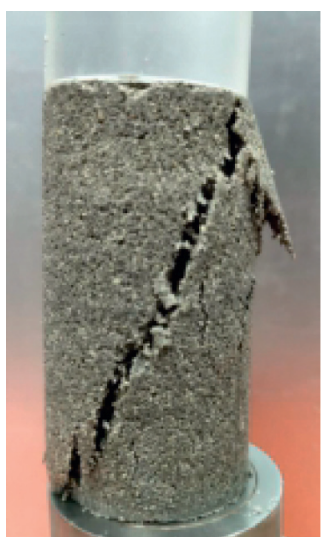

(a)

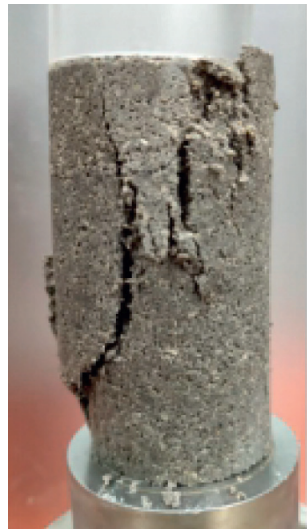

(b)

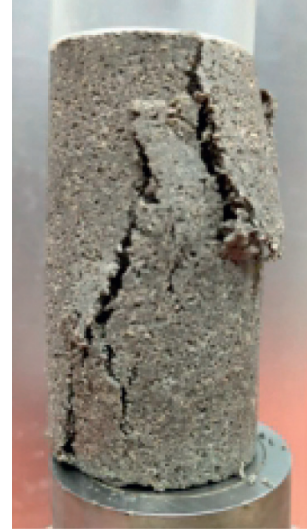

(c)

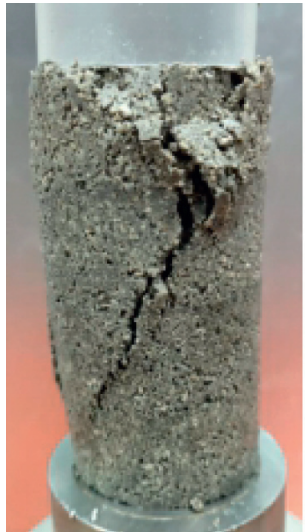

(d)

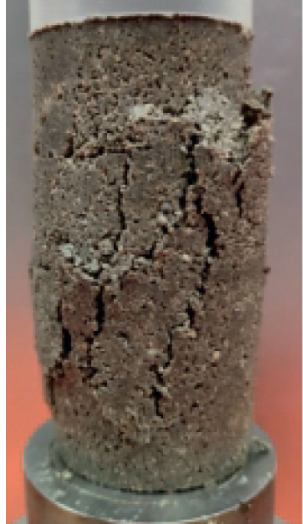

(e)

Figure 13: The destroying forms of CCS and NCCS on 28 d. (a) CCS. (b) NCCS-4. (c) NCCS-6. (d) NCCS-8. (e) NCCS-10.

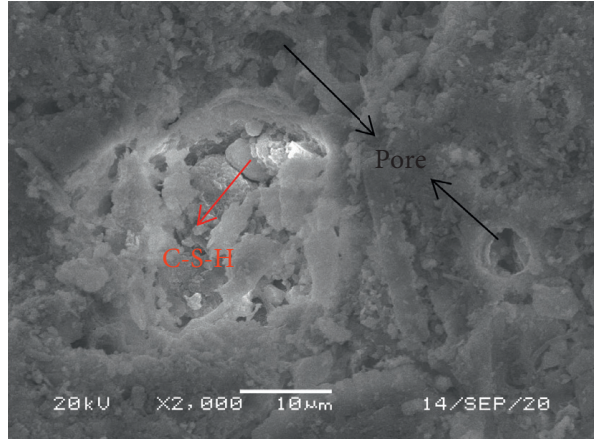

(a)

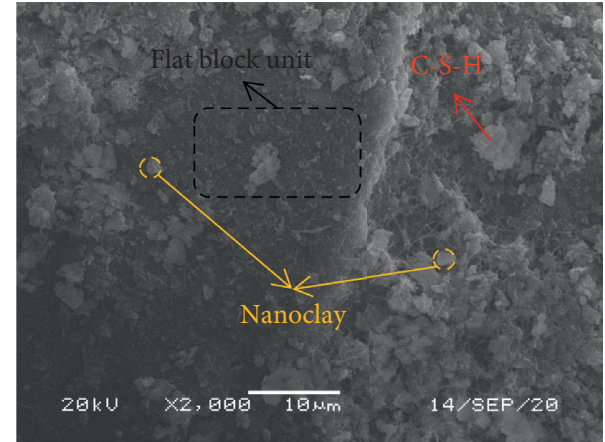

(b)

FIgURE 14: Microstructure of (a) CCS and (b) NCCS.

particles and flat block materials in the microstructure of NCCS. Compared with CCS, the pores in the microstructure of NCCS were significantly reduced, and a relatively complete flat block unit appears. The reasons could be attributed to (1) the size effect of nanoclay. The size of nanoclay particles was small, which could fill the pores of calcareous sand well. (2) The nucleation effect of nanoclay. Nanoclay could be used as the core to adsorb calcium ions in the sample and promote hydration reaction. Hamed et al. [40] obtained a similar conclusion. In conclusion, nanoclay could improve the compactness of the internal structure of CCS, so as to improve the compressive strength of CCS.

\section{Results and Analysis}

6.1. Results. From the unconfined compressive test and microscopic test, the unconfined mechanical characteristics and microscopic mechanism of CCS and NCCS were analyzed. Conclusions were obtained as follows:

(1) With different times, the stress-strain curves of CCS and NCCS were both softening curves.

(2) The nanoclay admixture could effectively improve the mechanical performance of CCS. The optimum admixture ratio of $8 \%$ was chosen for the nanoclay modified CCS. The mechanical performance with $7 \mathrm{~d}, 14 \mathrm{~d}$, and $28 \mathrm{~d}$ increased $43.9 \%, 64.4 \%$, and $77.6 \%$, respectively.

(3) The nanoclay admixture could increase the CCS deformed modulus and improve the resistance capacity against plastic deformation of CCS. By the linear simulation for the whole NCCS ratio with different nanoclay admixture, it can provide a reference for the design of practical engineering.

(4) The destroying modes of CCS and NCCS were all tilted fracture destroying. With the increase of nanoclay admixture, the numbers of the small cracks of NCCS increased accordingly.

(5) Due to the size effect and nucleation effect of nanoclay, the compactness of CCS internal structure and the mechanical properties of CCS could be improved.

\subsection{Analysis}

(1) The study was focused on the effect of nanoclay on the unconfined compressive strength of cement modified calcareous sand. The influence of confining 
pressure and cement content on the mechanical properties of calcareous sand needs further study.

(2) This study could provide a theoretical basis for practical engineering to use nanoclay and cement composite reinforcement of calcareous sand. However, how to apply it in practical engineering needs further study.

\section{Data Availability}

All the data used to support the findings of this study are included within the article.

\section{Conflicts of Interest}

The authors declare no conflicts of interest.

\section{Acknowledgments}

This study was supported by the National Natural Science Foundation of China (51968019 and 41772311), the High Level Talent Project of Hainan Basic and Applied Basic Research Plan (2019RC148 and 2019RC351), and the Hainan Natural Science Foundation (518QN307 and 519QN333).

\section{References}

[1] D. A. Smith and K. F. Cheung, "Initiation of motion of calcareous sand," Journal of Hydraulic Engineering, vol. 130, no. 5, pp. 467-472, 2004.

[2] K. Qian, X. Z. Wang, J. W. Chen, and P. J. Liu, "Experimental study on permeability of calcareous sand for islands in the South China sea," Rock and Soil Mechanics, vol. 38, no. 6, pp. 1557-1564+1572, 2017.

[3] Q. S. Chen, W. Peng, G. L. Tao, and S. Nimbalkar, "Strength and deformation characteristics of calcareous sands improved by PFA," KSCE Journal of Civil Engineering, vol. 11, pp. 1-10, 2020.

[4] M. Salem, H. Elmamlouk, and S. Agaiby, "Static and cyclic behavior of North Coast calcareous sand in Egypt," Soil Dynamics and Earthquake Engineering, vol. 55, pp. 83-91, 2013.

[5] H. Salehzadeh, D. C. Procter, and C. M. Merrifield, "Medium dense non-cemented carbonate sand under reversed cyclic loading," International Journal of Civil Engineering, vol. 4, no. 1, pp. 54-63, 2006.

[6] I. Ripley, A. J. C. Keulers, and S. G. Greed, "Conductor load tests," in Proceedings of the International Conference on Calcareous Sediments, pp. 429-438, Perth, Australia, March 1988.

[7] V. N. Ghionna, G. Caridi, and D. Porcino, "Undrained monotonic and cyclic simple shear behaviour of carbonate sand," Géotechnique, vol. 58, no. 8, pp. 635-644, 2010.

[8] Y. Dehnavi, H. Shahnazari, H. Salehzadeh, and R. Rezvani, "Compressibility and undrained behavior of Hormuz calcareous sand," Electronic Journal of Geotechnical Engineering, vol. 15, pp. 1684-1702, 2010.

[9] H. Shahnazari, Y. Jafarian, M. A. Tutunchian, and R. Rezvani, "Undrained cyclic and monotonic behavior of hormuz calcareous sand using hollow cylinder simple shear tests," International Journal of Civil Engineering, vol. 14, no. 4, pp. 209-219, 2016.
[10] J. R. Zhang, M. X. Luo, W. K. Peng, and B. W. Zhang, "Drained triaxial test on mechanical properties of calcareous sand under various stress paths," Chinese Journal of Geotechnical Engineering, vol. 12, no. 3, pp. 1-11, 2020.

[11] Y. Liu, F. H. Lee, S. T. Quek, E. J. Chen, and J. T. Yi, "Effect of spatial variation of strength and modulus on the lateral compression response of cement-admixed clay slab," Géotechnique, vol. 65, no. 10, pp. 851-865, 2015.

[12] R. Rasouli, M. H. Rad, and H. Salehzadeh, "A comparison between the undrained shear behavior of carbonate and quartz sands," International Journal of Civil Engineering, vol. 12, no. 4, pp. 338-350, 2014.

[13] X.-Z. Wang, Y.-Y. Jiao, R. Wang, M.-J. Hu, Q.-S. Meng, and F.-Y. Tan, "Engineering characteristics of the calcareous sand in nansha islands, south China sea," Engineering Geology, vol. 120, no. 1-4, pp. 40-47, 2011.

[14] Y. Xiao, H. Liu, Q. Chen, Q. Ma, Y. Xiang, and Y. Zheng, "Particle breakage and deformation of carbonate sands with wide range of densities during compression loading process," Acta Geotechnica, vol. 12, no. 5, pp. 1177-1184, 2017.

[15] Y. Xiao, H. Liu, P. Xiao, and J. Xiang, "Fractal crushing of carbonate sands under impact loading," Géotechnique Letters, vol. 6, no. 3, pp. 1-6, 2016.

[16] Y. H. Wang and S. C. Leung, "Characterization of cemented sand by experimental and numerical investigations," Journal of Geotechnical and Geoenvironmental Engineering, vol. 134, no. 7, pp. 992-1004, 2008.

[17] Y. Liu, L. Q. He, Y. J. Jiang, M. M. Sun, E. J. Chen, and F. H. Lee, "Effect of in situ water content variation on the spatial variation of strength of deep cement-mixed clay," Géotechnique, vol. 69, no. 5, pp. 391-405, 2019.

[18] K. Q. Li, D. Q. Li, and Y. Liu, "Meso-scale investigations on the effective thermal conductivity of multi-phase materials using the finite element method," International Journal of Heat and Mass Transfer, vol. 151, Article ID 119383, 2020.

[19] D. X. Wang, R. Zentar, and N. E. Abriak, "Durability and swelling of solidified/stabilized dredged marine soils with class-F fly ash, cement, and lime," Journal Of Materials In Civil Engineering, vol. 30, no. 3, pp. 1-12, 2018.

[20] R. H. Wang, D. Q. Li, M. Y. Wang, and Y. Li, "Deterministic and probabilistic investigations on piping occurrence during tunnelling through spatially variable soils, ASCE-ASME Journal of Risk and Uncertainty in Engineering Systems," Part A: Civil Engineering, 2021, In press.

[21] S. S. Sharma and M. Fahey, "Evaluation of cyclic shear strength of two cemented calcareous soils," Journal of Geotechnical and Geoenvironmental Engineering, vol. 129, no. 7, pp. 609-618, 2003.

[22] M. A. Ismail, H. A. Joer, W. H. Sim, and M. F. Randolph, "Effect of cement type on shear behavior of cemented calcareous soil," Journal of Geotechnical and Geoenvironmental Engineering, vol. 128, no. 6, pp. 520-529, 2002.

[23] D. Cui and H. Gao, "Advance and prospect of bionanomaterials,” Biotechnology Progress, vol. 19, no. 3, p. 683, 2010.

[24] P. Hosseini, A. Afshar, B. Vafaei, A. Booshehrian, E. Molaei Raisi, and A. Esrafili, "Effects of nano-clay particles on the short-term properties of self-compacting concrete," European Journal of Environmental and Civil Engineering, vol. 21, no. 2, pp. 127-147, 2017.

[25] K. Yao, D. An, W. Wang, N. Li, C. Zhang, and A. Zhou, "Effect of nano-mgo on mechanical performance of cement stabilized silty clay," Marine Georesources \& Geotechnology, vol. 38, no. 2, pp. 250-255, 2020. 
[26] K. Yao, W. Wang, N. Li, C. Zhang, and L. Wang, "Investigation on strength and microstructure characteristics of Nano-MgO admixed with cemented soft soil," Construction and Building Materials, vol. 206, pp. 160-168, 2019.

[27] W. Wang, Y. Li, K. Yao, A. Z. Zhou, and C. Zhang, "Strength properties of nano- $\mathrm{MgO}$ and cement stabilized coastal silty clay subjected to sulfuric acid attack," Marine Georesources and Geotechnology, vol. 38, pp. 1177-1186, 2019.

[28] S. Allalou, R. Kheribet, and A. Benmounah, "Effects of calcined halloysite nano-clay on the mechanical properties and microstructure of low-clinker cement mortar," Case Studies in Construction Materials, vol. 10, Article ID e00213, 2019.

[29] H. Mohamed, A. A.-G. Hamdy, and A. A. Fuad, "Positive impact performance of hybrid effect of nano-clay and silica nano-particles on composite cements," Construction and Building Materials, vol. 190, pp. 508-516, 2018.

[30] N. Li, S. W. Lv, W. Wang, J. Guo, P. Jiang, and Y. Liu, "Experimental investigations on the mechanical behavior of iron tailings powder with compound admixture of cement and nano-clay," Construction and Building Materials, vol. 254, Article ID 119259, 2020.

[31] H. M. Zaid, R. T. Mohd, T. J. Ibtehaj, and T. J. Taha, "Stabilization of soft soil using nanomaterials," Research Journal of Applied Sciences, vol. 8, no. 4, pp. 503-509, 2014.

[32] M. R. Irshidat, M. H. Al-Saleh, and A. Shanableh, "Effect of elevated temperatures on mechanical performance of cement mortar with nanoclay," MATEC Web of Conferences, vol. 120, Article ID 2005, 2017.

[33] JGJ/T 233-2011, Design Specification for Cement Soil Mix Proportion, China Construction Industry Press, Beijing, China, 2011.

[34] GB/T, Standard for Soil Test Method, China Planning Press, Beijing, China, 2019.

[35] Z. T. Hu and X. S. Liu, "A practical data fusion algorithm," Process Automation Instrumentation, vol. 8, pp. 7-9, 2005.

[36] T. Zhang, X. Yue, Y. Deng, D. Zhang, and S. Liu, "Mechanical behaviour and micro-structure of cement-stabilised marine clay with a metakaolin agent," Construction and Building Materials, vol. 73, pp. 51-57, 2014.

[37] G. A. Lorenzo and D. T. Bergado, "Fundamental characteristics of cement-admixed clay in deep mixing," Journal of Materials in Civil Engineering, vol. 18, no. 2, pp. 161-174, 2006.

[38] D. Wang, N. E. Abriak, and R. Zentar, "Strength and deformation properties of Dunkirk marine sediments solidified with cement, lime and fly ash," Engineering Geology, vol. 166, pp. 90-99, 2013.

[39] U. Khalid, C. C. Liao, G.-1. Ye, and S. K. Yadav, "Sustainable improvement of soft marine clay using low cement content: a multi-scale experimental investigation," Construction and Building Materials, vol. 191, pp. 469-480, 2018.

[40] N. Hamed, M. S. El-Feky, M. Kohail, and E.-S. A. R. Nasr, "Effect of nano-clay de-agglomeration on mechanical properties of concrete," Construction and Building Materials, vol. 205, pp. 245-256, 2019. 